\title{
Low sperm to egg ratio required for successful in vitro fertilisation in a 2 pair-spawning teleost, Senegalese sole (Solea senegalensis)
}

\author{
Sandra Ramos-Júdez ${ }^{1=}$, Wendy Ángela González-López ${ }^{1=}$, Jhons Huayanay Ostos ${ }^{1}$, \\ Noemí Cota Mamani ${ }^{2}$, Carlos Marrero Alemán ${ }^{1}$, José Beirão ${ }^{3}$, Neil Duncan ${ }^{1 *}$ \\ ${ }^{1}$ IRTA, Sant Carles de la Ràpita Ctra. de Poble Nou km. 5.5, 43540 Sant Carles de la Ràpita, Tarragona, Spain. \\ ${ }^{2}$ Dirección General de Investigaciones en Acuicultura, Instituto del Mar del Perú (IMARPE), Lima, Peru \\ 8 \\ ${ }^{3}$ Faculty of Biosciences and Aquaculture, Nord University, NO-8049 Bod $\varnothing$, Norway
} 4

\begin{abstract}
Cultured Senegalese sole (Solea senegalensis) breeders fail to spawn fertilised eggs and this bottleneck could be solved with the implementation of large-scale in vitro fertilisation protocols. However, low production of poor-quality sperm has frustrated the development of in vitro fertilisation protocols. Cultured females were induced to ovulate with a $5 \mu \mathrm{g}$ $\mathrm{kg}^{-1}$ single injection of gonadotropin releasing hormone agonist (GnRHa) and good quality eggs $(82.6 \pm 9.2 \%$ fertilisation) were stripped $41: 57 \pm 1: 46 \mathrm{~h}$ after the injection.

16 Sperm was collected from cultured males, diluted in modified Leibovitz and used fresh to fertilise the eggs. A non-linear regression, an exponential rise to a maximum $(R=0.93$, $18 \mathrm{P}<0.0001)$ described the number of motile spermatozoa required to fertilise a viable egg and 1617 motile spermatozoa were sufficient to fertilise $99 \pm 12 \%( \pm 95 \% \mathrm{CI})$ of viable

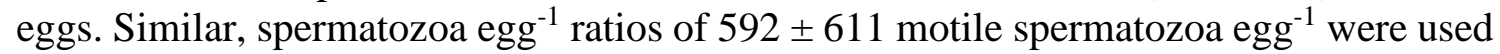
in large-scale in vitro fertilisations with $190,512 \pm 38,471$ eggs. The sperm from a single male $\left(145 \pm 50 \mu \mathrm{L}\right.$ or $8.0 \pm 6.8 \times 10^{8}$ spermatozoa) was used to fertilise the eggs. The mean hatching rate of the large-scale in vitro fertilisations was $70 \pm 14 \%$ to provide $131,540 \pm 34,448$ larvae per fertilisation. When unfertilised eggs were stored at room temperature the percentage of viable eggs decreased gradually and indicated the sooner

26 eggs were fertilised after stripping the higher the viability of the eggs. The collection of sperm directly into a syringe containing modified Leibovitz significantly increased the percentage of motile spermatozoa $(33.4 \pm 12.2 \%)$ compared to dilution in modified Leibovitz immediately after collection $(6.6 \pm 4.9 \%)$. Senegalese sole have a pairspawning reproductive behaviour characterised by external gamete fertilisation in close proximity with no sperm competition. The low spermatozoa $\mathrm{egg}^{-1}$ ratio required for maximum fertilisation was consistent with this reproductive behaviour and strategy. The provision of a large-scale in vitro fertilisation protocol $(200 \mu \mathrm{L}$ of sperm per $100 \mathrm{~mL}$ of eggs) will enable the industry to operate sustainably and implement breeding programs to improve production.
\end{abstract}




\section{Introduction}

40 Senegalese sole (Solea senegalensis) is a promising emerging aquaculture species in Europe. Sole production from land based farms in Spain, Portugal, France and Iceland has increased rapidly to 1,700 $\mathrm{t}$ in 2019 (APROMAR, 2019). This increase is driven by good market prices, high market demand and successful culture practices (Morais et al., 2016) that permit cost effective production despite of the need for high levels of investment in culture infrastructure.

However, the production cycle is not fully controlled and relies on the capture of wild broodstock that spawn sufficient eggs to achieve targeted aquaculture productions (Anguis and Cañavate, 2005; Martín et al., 2014). The progeny of these wild broodstock and in particular the males exhibit a reproductive behavioural dysfunction and do not participate in the courtship to fertilise eggs (Duncan et al., 2019; Fatsini et al., 2020; Guzmán et al., 2008; Martín et al., 2020). Consequentially, cultured broodstocks that were reared entirely in captivity produce unfertilised eggs (Duncan et al., 2019; Guzmán et al., 2008). Differences between wild and cultured breeders have suggested that the reproductive dysfunction has a bases in a combination of endocrine reproductive control (Guzmán et al., 2011; Riesco et al., 2019), social conditions during rearing (Fatsini et al., 2020; Martín et al., 2020), broodstock nutrition (Norambuena et al., 2013a, 2013b, 2012b, 2012c, 2012a) and olfactory capacity (Fatsini et al., 2017). However, no practical approach has been developed to overcome these reproductive dysfunctions and the low levels of fertilised egg obtained from cultured broodstocks (Fatsini et al., 2020; Guzmán et al., 2011) were insufficient to meet industry needs.

In flatfish culture, in vitro fertilisation methods are commonly used to obtain the fertilised eggs required for aquaculture (Mañanós et al., 2008). In vitro fertilisation enables aquaculturists to bypass behavioural reproductive dysfunctions of the type observed in cultured male Senegalese sole. However, the application of in vitro fertilisation methods for Senegalese sole has been frustrated by the small quantities of poor quality sperm produced by males (Beirão et al., 2011, 2009; Cabrita et al., 2011, 2006; González-López et al., 2020). Rasines et al. (2013, 2012), has described in vitro fertilisation procedures for Senegalese sole on an experimental scale. Female sole were induced to ovulate with gonadotropin releasing hormone agonist $(\mathrm{GnRHa})$ and batches of $1 \mathrm{~mL}$ of stripped eggs were fertilised with $30 \mu \mathrm{L}$ of cryopreserved sperm from cultured males. Similarly, Liu et al. (2008) described in vitro fertilisation of Senegalese sole eggs on an industrial scale. Again, eggs were obtained from GnRHa induced cultured females and all the eggs from each female were fertilised in vitro with the sperm from three to four cultured males. However, few details were given on the amount of sperm or eggs used and the spermatozoa (spz) to egg ratio was not detailed.

When sperm is limiting, it is of critical importance to know the spz to egg ratio (amount of spz required to fertilise each egg) to plan in vitro fertilisation procedures. Spermatozoa to egg ratios for in vitro fertilisation of fish eggs show considerable variation ranging from $\times 10^{3}$ to $\times 10^{6}$ (Beirão et al., 2019). However, it would appear that flatfish have lower spz requirements as winter flounder (Pseudopleuronectes americanus) required 3.4 $\times 10^{4} \mathrm{spz} \mathrm{egg}^{-1}$ (Butts et al., 2012) and turbot (Scophthalmus maximus) required just 3000 to $6000 \mathrm{spz} \mathrm{egg}^{-1}$ (Chereguini et al., 1999; Suquet et al., 1995). Many flatfish species have reproductive strategies and behaviours to spawn as a pair (Carazo et al., 2016; Gibson et al., 2014). Monogamous fish species (classified as species that spawn in a pair) were shown to have smaller testes compared to polyandrous species (group spawning of males with a female) (Baker et al., 2020). Monogamy or pair-spawning will also reduce sperm 
competition (sperm from two or more males compete to fertilise the eggs) and decreasing sperm competition has been related to smaller testes and lower sperm production (Parker and Pizzari, 2010; Stockley et al., 1997). Senegalese sole spawn as pairs (Carazo et al., 2016; Duncan et al., 2019) and spawning pairs show a degree fidelity during and between spawning seasons (Fatsini et al., 2020; Martín et al., 2014). Therefore, pair-spawning and low sperm competition would appear to explain the small testes size (García-López et al., 2005; González-López et al., 2020) and low sperm production reported for Senegalese sole (Beirão et al., 2011, 2009; Cabrita et al., 2011, 2006; González-López et al., 2020). In addition, a preliminary study found that Senegalese sole achieved a high percentage of fertilisation with a low spz to egg ratio (Marrero-Alemán et al., 2019) and indicated that in vitro fertilisation with the low numbers of sperm may be a viable solution to the industries problem to control the reproduction.

The present study, aimed to determine the spz to egg ratio required for in vitro fertilisation in Senegalese sole. The first aim was to determine the sperm to egg ratio on an experimental scale and then use similar ratios for commercial large-scale in vitro fertilisations as a proof-of-concept. Additional aims were, to determine the viability of ovulated eggs stored at room temperature and to improve sperm collection methods.

\section{Methods}

\subsection{Experimental animals}

106 All Senegalese sole broodstock used were cultured fish that had been hatched and reared entirely in captivity. Females used had an average weight of $1.53 \pm 0.28 \mathrm{~kg}$ and males

108 had a weight of $1.05 \pm 0.25 \mathrm{~kg}$. Fish were maintained in 10,000 L tanks in IRTA Sant Carles de la Rápita (Catalonia, Spain). Prior to experiments, fish were held in surface sea 110 water $\left(\sim 35 \mathrm{ppt},>5 \mathrm{mg} . \mathrm{L}^{-1} \mathrm{O} 2\right)$ and a controlled natural temperature cycle $\left(9-20^{\circ} \mathrm{C}\right)$ using recirculation systems (IRTAmar®). Tanks were covered with shade netting and

112 photoperiod was natural with natural light. The fish were fed four days a week with either unfrozen polychaetes and mussels $(0.75 \%$ of biomass $)$ or $5 \mathrm{~mm}$ pelleted Broodfeedlean

114 broodstock diet (0.55\% of biomass) (Sparos, Olhão, Portugal). During experiments conducted from April to June, fish were held in the same conditions with the exceptions

116 that water temperature was maintained at a constant $16 \pm 1{ }^{\circ} \mathrm{C}$ and fish were not feed 24 hours before any manipulation.

118 The fish were handled (routine husbandry and experimentation) in accordance with European regulations on animal welfare (Federation of Laboratory Animal Science

120 Associations, FELASA, http://www.felasa.eu/). For all handling and sampling, fish were anesthetised with $60 \mathrm{mg} \mathrm{L}^{-1}$ tricaine methanesulfonate (MS-222; Sigma-Aldrich, Spain).

\subsection{Gametes}

Eggs were obtained by inducing ovulation. Ovarian biopsies were taken from females

124 with swollen ovaries and the diameter of 20 oocytes were measured (x40 Carl Zeiss Axiostar microscope). Females were selected that had mean oocyte diameter $\geq 600 \mu \mathrm{m}$ 126 (Marrero-Alemán et al., 2019). The females were administered $5 \mu \mathrm{g} \mathrm{kg}^{-1}$ of $\mathrm{GnRHa}$ (Sigma code L4513, Sigma, Spain) (Agulleiro et al., 2006) between 18:00 to 19:00 h. The females were held with constant temperature $\left(16 \pm 1{ }^{\circ} \mathrm{C}\right)$ and total darkness until ovulation. Females were checked for ovulation every 2-3 hours starting from $40 \mathrm{~h}$ after the administration of GnRHa (Marrero-Alemán et al., 2019; Rasines et al., 2013, 2012) and all eggs were stripped from the ovulated females. Percentage fertilisation when spz were in excess was used to indicate egg quality. 
Sperm was obtained from males by repeatedly, gently massaging the testes and applying pressure along the full length of the sperm ducts to the urogenital pore. All sperm with urine contamination was collected in a $1 \mathrm{~mL}$ syringe. González-López et al. (2020), demonstrated that avoiding urine contamination was almost impossible and that high numbers of motile spz were obtained stripping sperm mixed with urine. The volume collected was measured with the syringe to an accuracy of $10 \mu \mathrm{L}$ and the sperm was transferred to a $1.5 \mathrm{~mL}$ Eppendorf and immediately diluted with modified Leibovitz

140 (González-López et al., 2020) using the dilution required for the experiment (see below). The sperm motility was initially observed (x 100 Carl Zeiss Axiostar microscope) by

142 activating $1 \mu \mathrm{L}$ of diluted sperm with $19 \mu \mathrm{L}$ of clean seawater. Sperm samples with low or no motility were rejected. All sperm samples were stored over ice or at $4^{\circ} \mathrm{C}$ 144 (refrigerated) until analysis or used to fertilise eggs.

The spz concentration ( $\mathrm{spz} \mathrm{mL}^{-1}$ ) was measured using a Thoma cell counting chamber. A $14610 \mu \mathrm{L}$ sample of sperm was diluted 1:500 in 10\% formalin and $10 \mu \mathrm{L}$ of the dilution was pipetted into the counting chamber. After 10 minutes for $\mathrm{spz}$ to sediment, the chamber was observed using a microscope (x100 magnification with Olympus BH microscope), photographed (IC Capture software and GigE digital camera model: DMK 22BUC03

150 Monochrome, The Imaginsource, Bremen, Germany) and the number of spz counted (ImageJ software, http://imagej.nih.gov/ij/).

152 Sperm motility parameters were determined as described by González-López et al. (2020). Spermatozoa were activated by mixing $1 \mu \mathrm{L}$ of diluted sperm (1:4 with modified

154 Leibovitz) with $20 \mu \mathrm{L}$ of seawater with $30 \%$ bovine serum albumin (BSA, Sigma, Spain). One $\mu \mathrm{L}$ of activated sperm was pipetted into an ISAS R2C10 counting chamber (Proiser $156 R+D$, S.L. Paterna, Spain) previously mounted and focused on the microscope (200x magnification Olympus $\mathrm{BH}$ ). Video recording was initiated when spz were activated and 158 tracks were recorded (IC Capture software and GigE digital camera) until motion ceased. Videos (AVI format) of spz tracks from 15 to $17 \mathrm{~s}$ (unless otherwise stated) after 160 activation were converted into image sequences (jpeg format using Virtual Dub 1.10.4 software http://www.virtualdub.org/). The image sequences were analysed using ImageJ

162 software with the computer-assisted sperm analysis (CASA) plugin (ImageJ http://rsb.info.nih.gov/ij/plugins/) using the settings: brightness and contrast, -10 to

$16415 / 224$ to 238 ; threshold, $0 / 198$ to 202 ; minimum sperm size (pixels), 10; maximum sperm size (pixels), 400; minimum track length (frames), 10; maximum sperm velocity 166 between frames (pixels), 30; frame rate, 30; microns/1000 pixels, 303; Print motion, 1; the additional settings were not modified. The parameters, percentage of motile spz (\% 168 motility), Curvilinear Velocity (VCL, $\mu \mathrm{m} / \mathrm{s}$ ) and Average Path Velocity (VAP, $\mu \mathrm{m} / \mathrm{s}$ ) were recorded. All sperm samples were analysed in triplicate.

170 The experiments (unless otherwise stated) aimed to use gametes (eggs and sperm) as soon as possible after collection to avoid possible loses of viability due to storage. Researchers

172 worked as two groups to strip eggs and sperm at the same time and complete in vitro fertilisations soon afterwards.

\subsection{Spermatozoa to egg ratio experiment}

Five different females and five different males were used during this experiment. When an ovulated female was encountered, sperm was collected and checked to find a male with $\geq 300 \mu \mathrm{L}$ of sperm that exhibited motility. The sperm was serially diluted with modified Leibovitz (González-López et al., 2020) to achieve eight dilutions: 1:4; 1:19; $1: 79 ; 1: 319 ; 1: 959 ; 1: 2879 ; 1: 5759 ; 1: 11519$. A sample of the first dilution $(1: 4)$ was used 
to determine the spz concentration and percentage motility. The spz concentration in the dilution 1:4 was used to calculate the spz concentration in each dilution and spz motility to calculate the concentration of motile spz. The eggs and diluted sperm were used to make three triplicate fertilisations for each serial dilution. Fertilisations were made in 100

$184 \mathrm{~mL}$ beakers by pipetting in close sequence, $0.5 \mathrm{~mL}$ of eggs, $20 \mu \mathrm{L}$ of diluted sperm and $5 \mathrm{~mL}$ clean seawater. A $1 \mathrm{~mL}$ pipette with a cut tip was used to pipette eggs and a $100 \mu \mathrm{L}$ pipette with a cut tip was used to pipette diluted sperm. The eggs, sperm and seawater were gently mixed by rocking and swirling the beaker. After 3-5 minutes, the volume of seawater was topped up to $100 \mathrm{~mL}$. The beakers of fertilised eggs were transferred to a $16{ }^{\circ} \mathrm{C}$ incubator. After 24 hours the eggs from each beaker were concentrated in a sieve and placed in a $10 \mathrm{~mL}$ Bogorov camber and $\geq 50$ eggs were randomly examined using a binocular microscope (Nikon C-DSS230) to determine the number of developing eggs. In addition, the number of eggs in three $0.5 \mathrm{~mL}$ samples was counted for each female.

\subsection{Proof-of-concept experiment}

194 Seven different females and seven different males were used during this experiment. The experiment aimed to make large-scale in vitro fertilisations using spz $\mathrm{egg}^{-1}$ ratios from

196 the previous experiment to fertilise the number of eggs (> 100,000 eggs) that would be required in a commercial fish farming scenario. When an ovulated female was 198 encountered, sperm was collected and checked to find a male with $\geq 150 \mu \mathrm{L}$ of motile sperm. The sperm was immediately diluted 1:4 in modified Leibovitz and a sample of 50

$200 \mu \mathrm{L}$ of diluted sperm was taken to determine spz concentration and percentage motility (CASA). All the eggs were stripped from the female into a clean, dry $1 \mathrm{~L}$ jug and the

202 volume of eggs was measured with an accuracy of $10 \mathrm{~mL}$. Three samples of $0.5 \mathrm{~mL}$ of eggs were taken and counted. The remaining sperm obtained from the male was added to

204 the eggs followed by a volume of seawater that was equal to the volume of eggs. The eggs, sperm and seawater were gently swirled to mix the contents. After 2-3 minutes the

206 jug was topped up to $1 \mathrm{~L}$ with seawater. The eggs were then divided into two or three parts and each part was placed in a $30 \mathrm{~L}$ incubator with the same conditions as the

208 broodstock holding tanks. The number of eggs in each incubator was estimated by mixing the incubator homogenously and taking three $100 \mathrm{~mL}$ samples and counting the eggs in

210 each sample. The eggs were left two days to hatch and the number of hatched larvae in each incubator was estimated as above for the eggs. The hatch rate was calculated from

212 the number of eggs stocked and number of larvae hatched and the mean was calculated for the replica incubators used for each female - male pair.

\section{$214 \quad 2.5$ Egg viability experiment}

Three different females and three different males were used during this experiment. When

216 an ovulated female was encountered, males were checked to find a male with $\geq 100 \mu \mathrm{L}$ of motile sperm. The sperm was immediately diluted 1:4 in Leibovitz. All the eggs were

218 stripped from the female into a clean, dry $1 \mathrm{~L} \mathrm{jug.} \mathrm{The} \mathrm{eggs} \mathrm{were} \mathrm{covered} \mathrm{and} \mathrm{stored} \mathrm{at}$ room temperature inside a building (out of sun light). As soon as possible after the 220 gametes were stripped the first fertilisation was completed as previously described. The time the eggs were stripped and the time the first fertilisation was made was recorded.

222 Further fertilisations were completed at 30 to 60 minute intervals. Fertilisations were completed in duplicate or triplicate using $0.5 \mathrm{~mL}$ of eggs and $20 \mu \mathrm{L}$ of diluted sperm that 224 ensured an excess of motile spz per egg. As described above, the beakers of fertilised eggs were transferred to a $16^{\circ} \mathrm{C}$ incubator and after 24 hours the percentage of developing eggs was determined for each fertilisation. 


\subsection{Sperm collection experiment}

228 Thirteen males were used for this experiment. Sperm from each male was collected as previously described, with the exception that the sperm was collected either into an empty

230 clean syringe ( $100 \mu \mathrm{L}$ of sperm) or into a syringe that contained modified Leibovitz (to give a 1:4 dilution, $50 \mu \mathrm{L}$ of sperm collected into $200 \mu \mathrm{L}$ of Leibovitz). Both collection 232 methods were used for each male and the sequence of collection was alternated. For seven animals sperm was first collected into a clean syringe and then into a syringe that

234 contained modified Leibovitz and for six animals the reverse, first directly into modified Leibovitz and then a clean syringe. The $100 \mu \mathrm{L}$ of sperm collected into a clean syringe

236 was immediately divided into $50 \mu \mathrm{L}$ that was diluted in $200 \mu \mathrm{L}$ of Leibovitz (1:4 dilution) and $50 \mu \mathrm{L}$ that was kept as undiluted sperm as a control. The time of collection and 238 dilution after collection was recorded. The sperm motility parameters were analysed (CASA) for the samples collected by these three methods: collected directly into

240 Leibovitz, collected before dilution in Leibovitz and undiluted sperm. Sperm motility parameters were analysed $30 \mathrm{~s}$ after activation for $2 \mathrm{~s}$. The parameters were measured at 242 the time of collection $(0 \mathrm{~h})$, six and $24 \mathrm{~h}$ after collection.

\subsection{Data analysis and statistics}

244 All means are with one standard deviation unless otherwise stated. For the spermatozoa $\mathrm{egg}^{-1}$ ratio experiment, the percentage of viable eggs fertilised was calculated by dividing

246 the actual fertilisation rate by the mean fertilisation rate when sperm was in excess. The number of motile sperm was calculated by multiplying the volume of diluted sperm added

248 by the spermatozoa concentration and the percentage motility. To examine the effect that gamete quality amongst the five pairs of fish had on fertilization, a linear regression was

250 applied to percentage of motile sperm (sperm quality) against number of sperm (motile and immotile) required per viable egg and to percentage of viable eggs (egg quality)

252 against number of motile sperm required per egg. To describe the variation of percentage of viable eggs fertilised in relation to the number of motile spz per egg, a non-linear

254 regression based on an equation for an exponential rise to a maximum with double, five parameters was applied to the data. For the egg viability experiment, the percentage of

256 viable eggs fertilised was calculated as above. To describe the variation of percentage of viable eggs fertilised in relation to time the eggs were stored at room temperature a non-

258 linear regression based on an equation for a four parameter logistic curve was applied to the data.

260 The data set for percentage motility from the sperm collection experiment was not normally distributed with a high percentage of zeros and skewed positively to a few

262 higher values. The data set could not be transformed to normality. The data was analysed twice. In one analysis, the data from the time point zero was ranked and analysed with a 264 two-way ANOVA with the independent variables order of collection $\left(1^{\text {st }}\right.$ or $\left.2^{\text {nd }}\right)$ and collection treatment (collected directly into Leibovitz, diluted in Leibovitz and undiluted sperm). In a second analysis the data set was scored into samples with or without motility and a Chi squared analysis was make to compare expected proportions of samples with motility with actual proportions with motility between sperm collection treatments (collected directly into Leibovitz, diluted in Leibovitz and undiluted sperm) and time of

270 storage ( $0 \mathrm{~h}, 6 \mathrm{~h}$ and $24 \mathrm{~h}$ ). The Marascuillo procedure (Prins, 2012) was used to make a multiple comparison between proportions of individual treatments and time points. All the samples with motility were then separated (i.e. all the zeros were excluded) into a smaller data set that was transformed to normality with the Logit transformation. The transformed data was compared with a one way ANOVA followed by Holm-Sidak 
pairwise multiple comparison to compare mean motility for each treatment at each time point. A $\mathrm{P}<0.05$ was used to indicate significant differences. All statistical comparisons and regressions were made using Sigma Plot 12 (Systat Software, Inc., San Jose, CA

278 95110. USA) except for the Marascuillo procedure that was completed with an Excel (Microsoft) worksheet written by the authors.

\section{$280 \quad 3.0$ Results}

A total of 46 males were checked to obtain $28(60.9 \%)$ males with the required sperm quantity and quality for the experiments. All males were only used once. A total of 20 females were selected by ovarian swelling and oocyte diameter determined. Five females

284 were rejected as the ovaries contained ovulated ova and two as the ovaries had solid cysts. A total of 13 females had oocytes $\geq 600 \mu \mathrm{m}$ and were induced with GnRHa. Five females

286 were not used as four females did not ovulate and one female had low quality eggs $(0 \%$ fertilisation). Eight (62\%) females ovulated good quality eggs that were used in the different experiments. The eggs from some females were used for more than one experiment. The mean latency time from injection with GnRHa to the ovulation was $29041: 57 \pm 1: 46 \mathrm{~h}$ and mean fertilisation was $82.6 \pm 9.2 \%$. The mean fecundity was 130,789 $\pm 36,723 \mathrm{eggs} \mathrm{fish}^{-1}$ or $87,174 \pm 24,378 \mathrm{egg} \mathrm{kg}^{-1}$ of female body weight. The maximum time difference between stripping eggs and sperm was 30 minutes, therefore, either sperm or eggs were stored for $30 \mathrm{~min}$ or less before fertilisation experiments were initiated.

\subsection{Spermatozoa to egg ratio experiment}

The percentage of viable eggs fertilised in relation to number of motile spz per egg showed a rapid increase from zero that was represented by a non-linear regression based on an equation for an exponential rise to a maximum with double, five parameters $(\mathrm{R}=$ $0.93, \mathrm{P}<0.0001$ ) (Fig. 1). The non-linear regression described that only 326 motile spz per egg fertilised $79 \pm 15 \%( \pm 95 \% \mathrm{CI}$ - confidence interval) of viable eggs, that 649 motile sperm fertilised $90 \pm 13 \%( \pm 95 \% \mathrm{CI})$ of viable eggs and 1617 motile spz fertilised $99 \pm 12 \%( \pm 95 \% \mathrm{CI})$ of viable eggs.

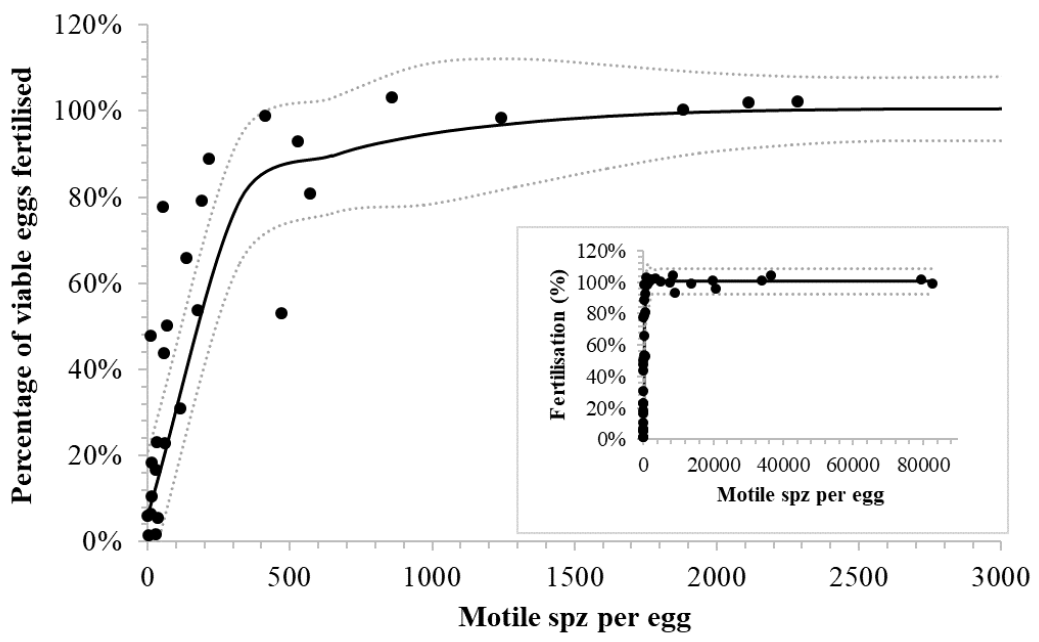

Figure 1. The percentage of viable eggs fertilised in relation to the number of motile spermatozoa (spz) per viable egg for Senegalese sole (Solea senegalensis). The insert figure shows the entire data set up to over 80,000 spz per egg and the large figure shows a close up of the data up to 3,000 motile spz per egg. The continuous line shows a non-linear regression based on an equation for an exponential rise to a maximum with double, five parameters $(\mathrm{R}=0.93, \mathrm{P}<0.0001)$ that represents the variation in percentage of viable eggs fertilised in relation to number of motile sperm per egg. The dotted lines indicate $95 \%$ confidence intervals for the non-linear regression. 
310 Amongst the five pairs, the percentage motility of the spz was correlated to the number of $\operatorname{spz}$ (motile and non-motile) required to fertilise a viable egg $\left(\mathrm{R}^{2}=0.83, \mathrm{P}=0.021\right)$.

312 However, there was no correlation between percentage of viable eggs and number of motile sperm required to fertilise each egg $\left(\mathrm{R}^{2}=0.03, \mathrm{P}=0.37\right)$. Caution is required in

314 the interpretation as $n$ was low $(n=5)$ and the statistical power (at $\alpha=0.05)$ of the tests was 0.66 and 0.13 , respectively for percentage motility and viable eggs.

\section{$316 \quad 3.2$ Proof-of-concept experiment}

The proof-of-concept large-scale in vitro fertilisations $(n=7)$ gave a mean percentage hatch of $70 \pm 14 \%$ to produce a mean of 131,540 $\pm 34,448$ larvae per fertilisation (Table 1). The sperm from a single selected cultured male with a volume of $145 \pm 50 \mu \mathrm{L}$ and

320 total spz count of $8 \pm 6.8 \times 10^{8}$ was sufficient to fertilise large numbers of eggs $(190,512$ $\pm 38,471)$ and produce large numbers of larvae $(131,540 \pm 34,448)$. The mean number of

322 spz per egg used for the commercial fertilisations was $2,981 \pm 2,932 \mathrm{spz} \mathrm{egg}^{-1}$ or $592 \pm$ 611 motile spz egg $^{-1}$.

\section{$324 \quad 3.3$ Egg viability experiment}

The percentage of viable eggs fertilised decreased gradually from after being stripped

326 (Fig. 2). The non-linear regression based on an equation for a four parameter logistic curve $(\mathrm{R}=0.80, \mathrm{P}=0.008)$ represented the variation in percentage of viable eggs fertilised in relation to the time eggs from the three females were stored at room temperature. The non-linear regression indicated that after $30 \mathrm{~min}$, the percentage fertilisation had decreased from $100 \%$ to $81 \pm 26 \%$ ( $\pm 95 \% \mathrm{CI}$ ), after an hour to $57 \pm 20 \%$ $( \pm 95 \% \mathrm{CI})$ and after two hours $32 \pm 19 \%( \pm 95 \% \mathrm{CI})$ fertilisation of viable eggs.

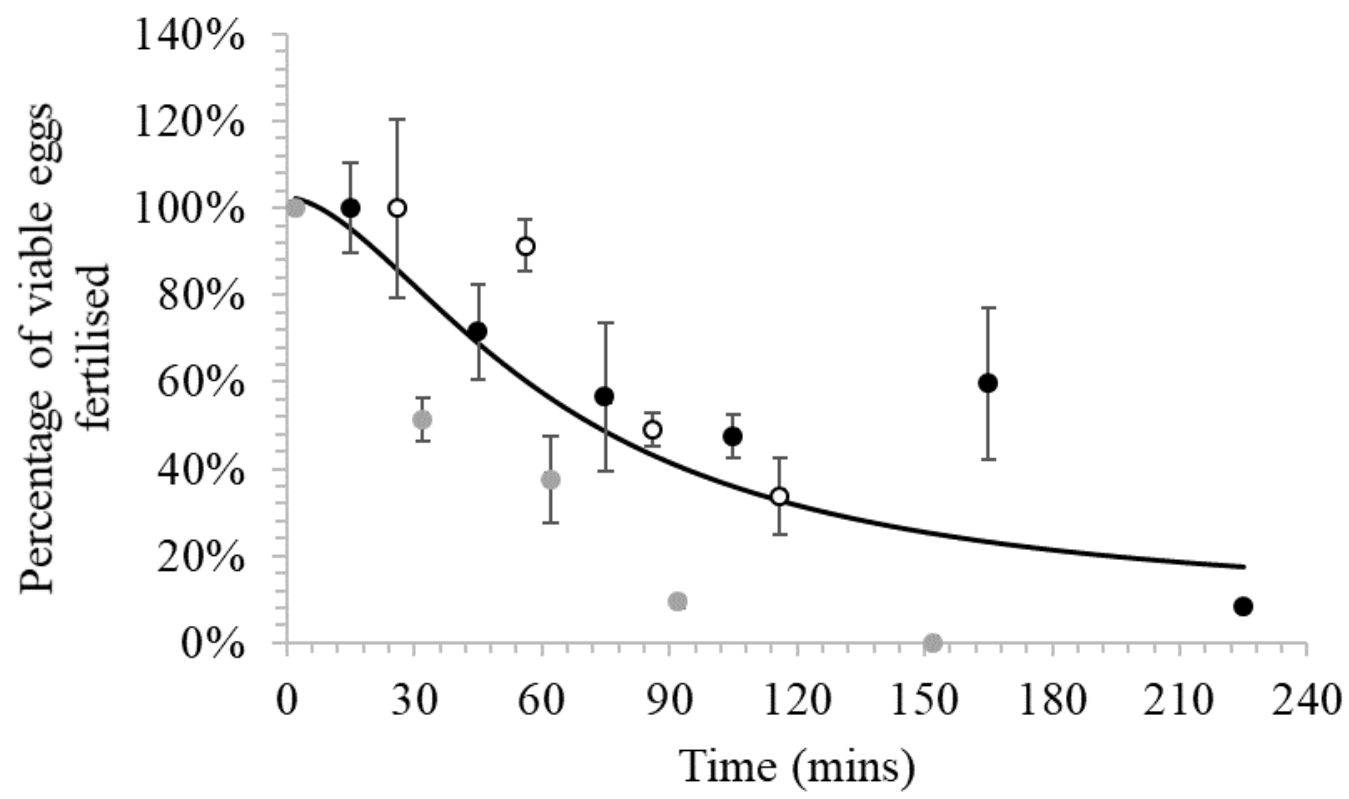

332

334

336

Figure 2. The percentage of viable eggs fertilised in relation to time eggs were stored at room temperature for three Senegalese sole (Solea senegalensis) females. Different dots represent different females. The line shows a non-linear regression based on an equation for a four parameter logistic curve ( $R$ $=0.08, \mathrm{P}=0.008$ ) that represents the variation in percentage of viable eggs fertilised in relation to time the eggs from the three females were stored. 
Table 1. Data from seven commercial scale in vitro fertilisations made for Senegalese sole (Solea senegalensis). Latency time from application of GnRHa ( 5 g $\mathrm{kg}^{-1}$ ) to stripping of ovulated eggs, volume of eggs used, total number of eggs used, volume of sperm used (sperm from single male before dilution), total number of spermatozoa (spz) added, number of spz per egg added, percentage motility of spz, number of motile spz per egg, mean percentage hatch in incubators and total number of larvae produced.

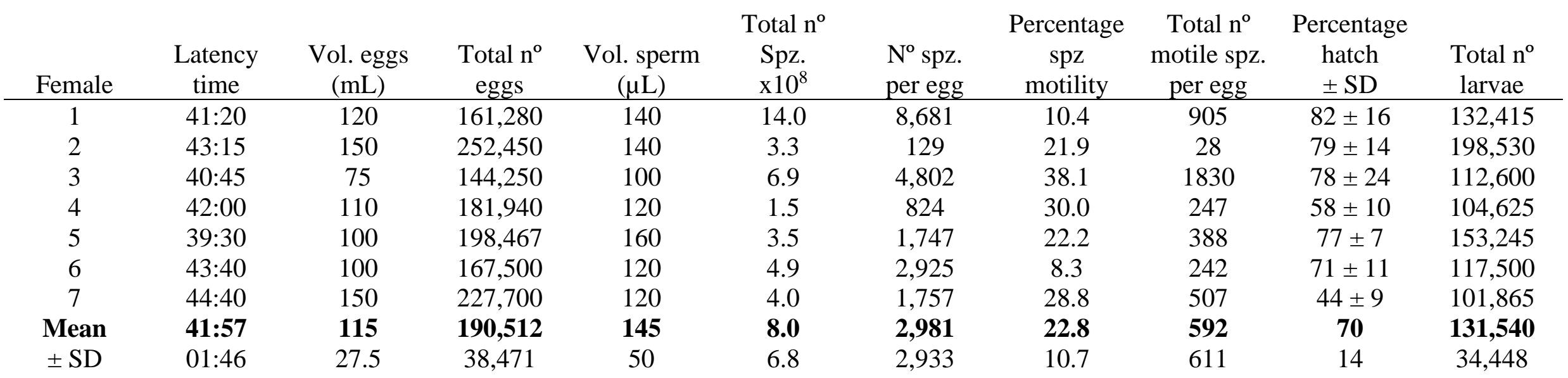




\subsection{Sperm extraction experiment}

The order of collection of the sperm appeared to have a significant effect and the first part 344 of the sperm collected had significantly $(\mathrm{P}=0.04)$ higher motility than the second part (Fig. 3). However, caution is required in the interpretation as there was considerable variation and the statistical power of the test was low (at $\alpha=0.05$, power $=0.44$ ). The percentage of samples that had motility decreased significantly $(\mathrm{P}<0.001)$ with time (Fig. 4). At the time of collection $(t=0)$ there were no differences in the percentage of samples with motility, but after six and $24 \mathrm{~h}$ of storage at $4^{\circ} \mathrm{C}$ the samples collected directly into modified Leibovitz had significantly $(\mathrm{P}<0.05)$ more samples with motility.

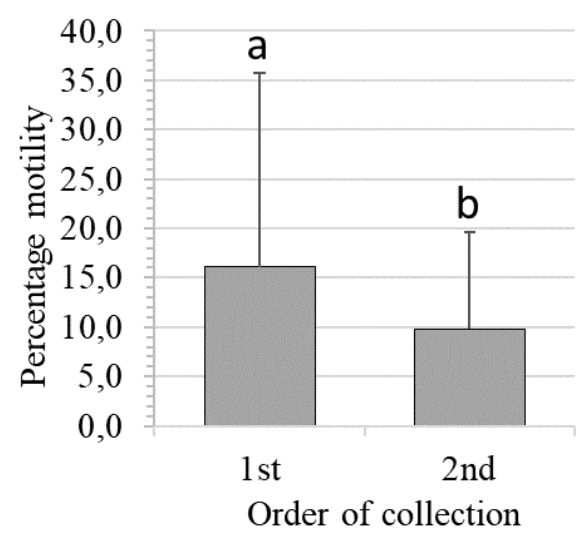

Figure 3. Mean percentage motility ( \pm 1 standard deviation) of sperm samples collected first or second from each Senegalese sole (Solea senegalensis) male. Different letters indicate a significant difference $(\mathrm{P}=0.04, \alpha=0.05$, power $=0.44)$.

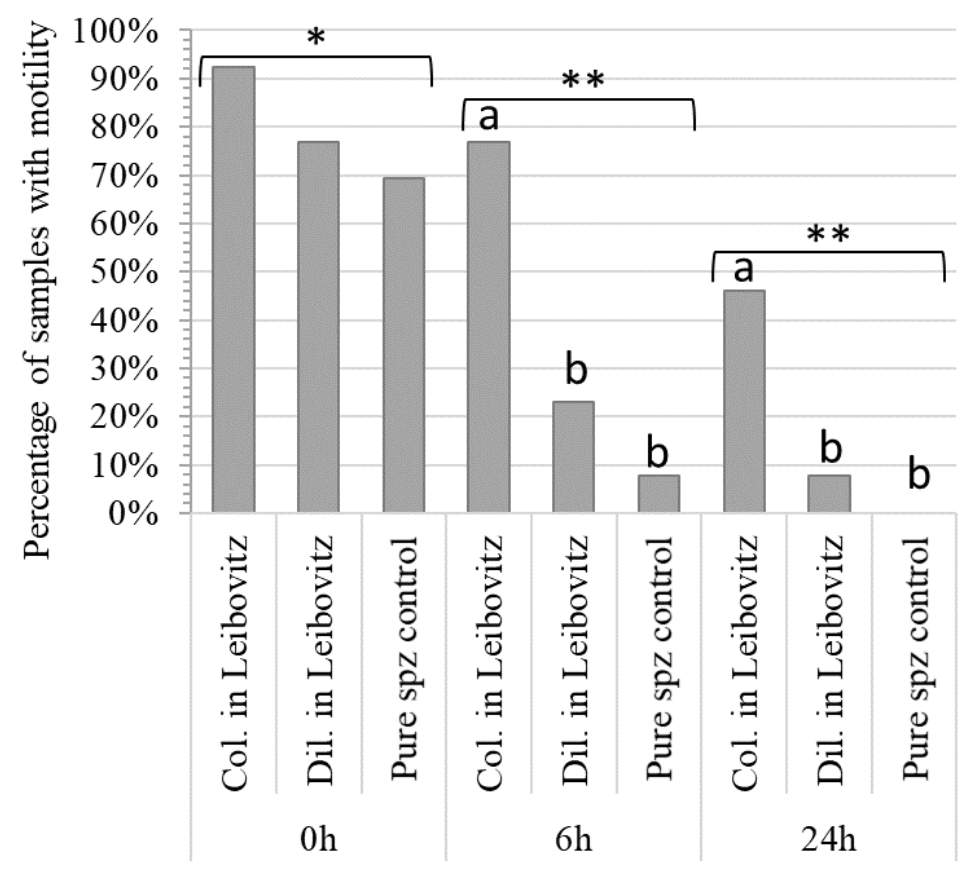

356 Figure 4. The percentage of sperm samples from Senegalese sole (Solea senegalensis) $(\mathrm{n}=13)$ that had sperm motility for different time points $0 \mathrm{~h}$ after collection and after six $(6 \mathrm{~h})$ and 24 hours $(24$ h) of storage at $4^{\circ} \mathrm{C}$. Three sperm collection methods were tested, collected directly into modified Leibovitz (Col. in Leibovitz), diluted in modified Leibovitz (Dil. in Leibovitz) after collection and undiluted sperm (control). Different letters indicate a significant difference $(\mathrm{P}<0.05)$ within a time point and different number of asterisk indicate significant difference $(\mathrm{P}<0.05)$ between time points. 
362 The percentage motility was significantly higher $(\mathrm{P}<0.05)$ in samples collected directly into modified Leibovitz at $\mathrm{t}=0$ compared to other time points $(\mathrm{t}=6$ and 24$)$ and other collection methods, diluted in modified Leibovitz and undiluted (control), at all time points ( $\mathrm{t}=0,6$ and 24) (Fig. 5). The motility of samples collected directly into Leibovitz and stored for six hours was significantly $(\mathrm{P}<0.05)$ higher than undiluted sperm samples at collection $(\mathrm{t}=0)$. The time difference in mixing sperm with Leibovitz was $4 \pm 2$ minutes, between samples collected directly into Leibovitz and the sperm diluted in Leibovitz after collection.

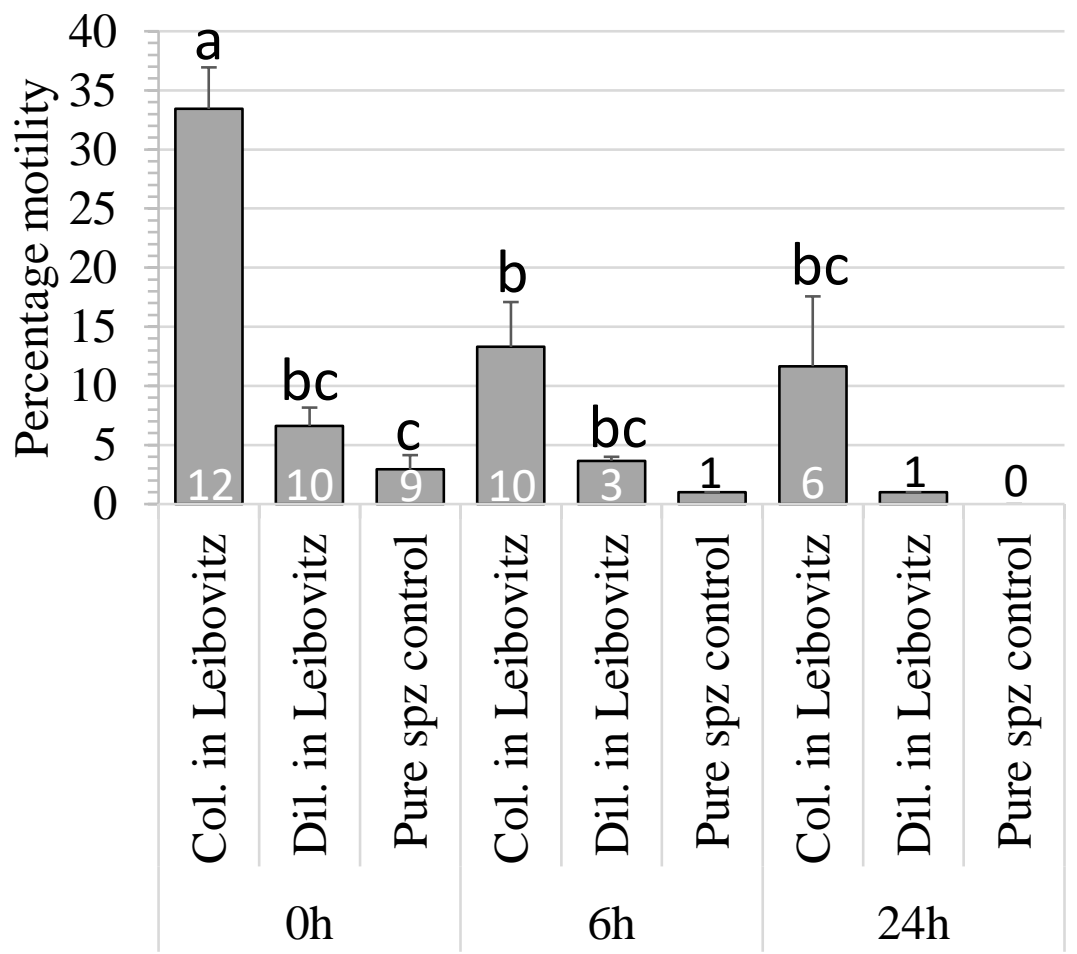

Figure 5. Mean percentage motility ( \pm 1 standard error of the mean) of sperm samples collected from Senegalese sole (Solea senegalensis) using three collection methods, collected directly into modified Leibovitz (Col. in Leibovitz), diluted in modified Leibovitz (Dil. in Leibovitz) after collection and undiluted sperm (control). The motility of samples was tested at different time points $0 \mathrm{~h}$ after collection and after six $(6 \mathrm{~h})$ and 24 hours $(24 \mathrm{~h})$ of storage at $4^{\circ} \mathrm{C}$. Different letters indicate a significant difference $(\mathrm{P}<0.05)$ amongst collection methods and time points. The " $\mathrm{n}$ " of each mean is at the bottom of each column. Means with less than $n=3$ were not included in the statistical test.

\subsection{Discussion}

\subsection{Low spermatozoa to egg ratio in Senegalese sole}

The present study demonstrated that low numbers of spermatozoa egg $^{-1}$ ensured high levels of fertilisation in Senegalese sole. An exponential rise to a maximum $(\mathrm{R}=0.93, \mathrm{P}$ $<0.0001$ ) described the number of motile spz required to fertilise a viable egg, the relationship rose steeply from 0 to $90 \%$ fertilisation and from approximately 500 motile spz plateaued at 90 to $100 \%$ fertilisation. A total of 1617 motile spz per egg were sufficient to fertilise $99 \pm 12 \%$ ( $\pm 95 \% \mathrm{CI})$ of viable eggs. A low mean spz egg ${ }^{-1}$ ratio also gave high rates of hatching in the proof-of-concept trials with large-scale in vitro fertilisations. A mean of 190,512 $\pm 38,471 \mathrm{eggs}$ from a single female were fertilised with a mean volume of sperm of $145 \pm 50 \mu \mathrm{L}$ from a single male. This volume of sperm 
provided a mean of $592 \pm 611$ motile spz per viable egg, which was sufficient to achieve $70 \pm 14 \%$ hatch and produce 131,540 $\pm 34,448$ larvae per in vitro fertilisation. The spz $\mathrm{egg}^{-1}$ ratios for Senegalese sole were at the lower end of ratios required for fish. Studies

392 have shown that different fish species require a wide range of $\mathrm{spz}^{\mathrm{egg}} \mathrm{g}^{-1}$ ratios to achieve high rates of fertilisation (Beirão et al., 2019). These ratios ranged from $3000 \mathrm{spz} \mathrm{egg}^{-1}$

394 for turbot (Chereguini et al., 1999) to $1 \times 10^{5} \mathrm{spz} \mathrm{egg}^{-1}$ for Atlantic cod (Gadus morhua) (Butts et al., 2009). Large-scale in vitro fertilisations protocols used in a hatchery 396 generally refer to the volume of sperm needed to fertilise eggs, for example in rainbow trout $1 \mathrm{~mL}$ of sperm was recommended for 10,000 eggs (Bromage, 1992) and for Atlantic

398 halibut (Hippoglossus hippoglossus) $1 \mathrm{~mL}$ of sperm for $1 \mathrm{~L}$ of eggs (Brown, 2010). For Senegalese sole, the present study has shown that a conservative estimation for hatcheries 400 based on the experiments and the $95 \%$ standard deviations, would be $200 \mu \mathrm{L}$ of sperm $(\approx$ $2.5 \times 10^{8}$ motile spz) to fertilise $100 \mathrm{~mL}$ of eggs $(\approx 150,000 \mathrm{eggs})$.

\subsection{Improved in vitro protocol}

An aspect that complicates in vitro fertilisation protocols is ensuring good gamete quality 404 for fertilisation. Generally, the sperm is obtained first and stored until eggs are obtained (Mylonas et al., 2017). Considering that Senegalese sole sperm has poor quality

406 (González-López et al., 2020) and eggs have a short period of viability (Rasines et al., 2013, 2012), the storage of eggs and collection methods of sperm were examined in the 408 present study to improve the in vitro fertilisation protocol. In addition, the present study ensured sperm or eggs were not stored for longer than 30 minutes before fertilisation to

410 limit the effect of gamete quality deterioration. This proved to be necessary as the decline in quality of stripped Senegalese sole eggs stored at room temperature was gradual and

412 continuous. Egg quality appeared to decline during the first $30 \mathrm{~min}$ of storage with no plateau period of good egg quality, which indicated the sooner eggs were fertilised after

414 stripping the higher the viability of the eggs. This decline in egg quality after ovulation and stripping has been described in a wide range of species as the overripening process,

416 where eggs age and in association with morphological and biochemical changes lose viability and fertilisation rates decline (Mañanós et al., 2008; Ramos-Júdez et al., 2019;

418 Samarin et al., 2011). A rapid decline in egg quality has been observed in other species, but the decline was initiated after a period of good egg quality of $1 \mathrm{~h}$ in curimata

420 (Prochilodus marggravii) (Rizzo et al., 2003) and $50 \mathrm{~min}$ in meagre (Argyrosomus regius) (Ramos-Júdez et al., 2019). There is considerable variation across species and

422 some species have very different egg storage capacities, for example eggs from a Cyprinidae species kutum (Rutilus frisii) (Samarin et al., 2011) maintained good egg 424 quality during eight hours of storage and salmonid eggs can be stored successfully for 45 days (Bromage, 1992).

426 To improve sperm quality different methods of sperm collection were compared. The collection of sperm directly into modified Leibovitz significantly increased motility at the 428 time of collection and the storage capacity in terms of motility and number of samples with motility. Senegalese sole sperm is difficult or impossible to collect without urine 430 contamination (González-López et al., 2020). The urine has negative effects on the sperm quality, which as in other species appeared to change osmolality and $\mathrm{pH}$, which

432 prematurely activated spz (Cejko et al., 2010; González-López et al., 2020; Linhart et al., 2003; Perchec Poupard et al., 1998). The collection into modified Leibovitz mitigated the 434 negative effect of urine contamination to improve the sperm quality (González-López et al., 2020). Other studies on species where urine contamination was difficult to avoid have focused on improved collection methods that reduce urine contamination with the use of 
catheters that were inserted into the sperm duct (Babiak et al., 2006; Sarosiek et al., 2016) or used a collecting pipette in combination with vacuum aspiration (Gallego et al., 2013a). The very small volumes and small diameter of the urogenital pore in Senegalese sole

440 make these kinds of approaches difficult or impossible. Small volumes of contaminated sperm obtained from some species of birds were collected directly into syringes with 442 extender to maintain sperm quality (Personal communication, Dr. Ignacio Giménez Nebot, Rara Avis Biotec S.L., Valencia, Spain). Therefore, in the present study, this 444 approach was taken to reduce the time that spz were in contact with urine contamination before dilution in the Leibovitz extender. A significant improvement in sperm quality was 446 obtained by collecting the sperm directly into a syringe containing modified Leibovitz, which reduced by $4 \pm 2$ minutes the time before sperm was diluted with Leibovitz.

4.3 Sustainable Senegalese sole aquaculture

The success of massive in vitro fertilisations, combined with indications of egg viability during storage and improved methods for collecting and managing sperm, provided a protocol that can be used on an industrial scale to obtain eggs from cultured breeders for

452 hatchery production. At present, the Senegalese sole aquaculture industry relies on obtaining eggs from wild adult breeders captured in the commercial fishery and there is 454 no sustainable fishery for Senegalese sole (https://fisheries.msc.org). Therefore, obtaining viable eggs from cultured breeders has been a bottleneck that makes the industry unsustainable and unable to implement breeding programs. Breeding programs are an essential part of an aquaculture business plan that enable companies to improve growth and product quality. However, ideally, reproduction must be controlled to enable the selection and production of viable gametes from any animal that has the desired production traits. In the present study, $61 \%$ of the males checked for sperm had the required quantity and quality needed for the experiments and in vitro fertilisations. This 462 availability of males, has already be improved as therapies with recombinant gonadotropins exist that both increase sperm production and quality (Chauvigné et al.,

$4642018,2017)$. These recombinant gonadotropin therapies, significantly increased sperm production by up to seven times and significantly increased the sperm quality parameters, percentage motility, progressivity and velocity of spz.

In the present study, females were initially selected by ovarian swelling and it is unclear what percentage of females would be available for selection over a reproductive season. Of the females that were GnRHa-induced, $62 \%$ ovulated good quality eggs. Therefore, 470 studies are needed to identify the number of females available for GnRHa induction and to improve the success rate of GnRHa inductions. The present study used a GnRHa dose 472 of $5 \mu \mathrm{g} \mathrm{kg}^{-1}$ to induce the ovulation of eggs compared to $25 \mu \mathrm{g} \mathrm{kg}^{-1}$ used by Rasines et al. $(2013,2012)$. These studies had similar holding conditions and temperature $\left(16^{\circ} \mathrm{C}\right)$ and 474 obtained very similar timing of ovulation with means close to $42 \mathrm{~h}$ (range of 39 to $44 \mathrm{~h}$ ). Egg quality appeared to be higher in the present study, but differences in methods and

476 particular sperm storage and usage make comparisons inappropriate. Different doses of GnRHa have been compared to induce spontaneous liberations of eggs in Senegalese sole.

478 Agulleiro et al. (2006), tested the injection of GnRHa doses of one, five and $30 \mu \mathrm{g} \mathrm{kg}^{-1}$. The dose of $5 \mu \mathrm{g} \mathrm{kg}^{-1}$ produced the most eggs and the dose of $30 \mu \mathrm{g} \mathrm{kg}^{-1}$ produced no 480 liberations of eggs. Guzman et al. (2009) compared injections of 5 and $25 \mu \mathrm{g} \mathrm{kg}^{-1} \mathrm{of}$ GnRHa, but found no differences in number of eggs released between GnRHa injected and untreated control fish. However, the number of oocytes advancing to hydration in the females treated with $5 \mu \mathrm{g} \mathrm{kg}^{-1}$ appeared to be higher than in females treated with $25 \mu \mathrm{g}$ $\mathrm{kg}^{-1}$ and controls. The present study, combined with studies on GnRHa induced 
spontaneous liberations of eggs, would indicate that the lower dose of $5 \mu \mathrm{g} \mathrm{kg}^{-1}$ of GnRHa provided similar ovulation timing and egg quality as $25 \mu \mathrm{g} \mathrm{kg}^{-1}$ and perhaps suggest that better results may be obtained with lower doses.

\subsection{Gamete quality and fertilisation}

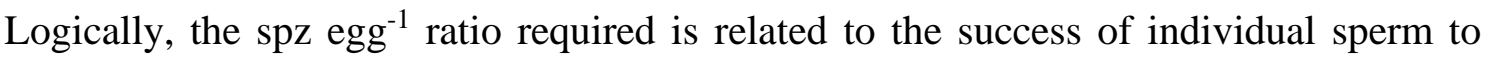

490 fertilise an egg. The success of spz will depend on factors of the fertilisation environment and gamete quality / characteristics that hinder or aid the spz to reach the micropyle of

492 the egg. The environment used for in vitro fertilisation has been shown to affect the spz $\mathrm{egg}^{-1}$ ratio. For example, the volume or space provided for fertilisation affected the spz

$494 \mathrm{egg}^{-1}$ ratio, as larger volumes increased the space to be travelled to fertilise the egg and increased the number of spz required (Bombardelli et al., 2013; Chereguini et al., 1999;

496 Sanches et al., 2016). Therefore, variation in the fertilisation environment complicates the comparison of different studies within and amongst species. However, as in the

498 present study the fertilisation environment can be standardised between tests and replicated to ensure results can be compared.

500 Gamete characteristics and / or quality vary amongst species and individuals. Variations

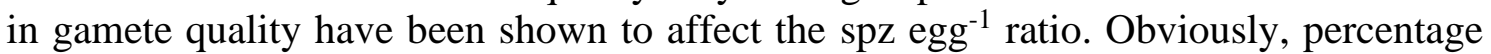
502 sperm motility affects the ratio (Gallego et al., 2013b; Moccia and Munkittrick, 1987), but velocity has also been shown to affect the ratio in walleye (Sander vitreus)

504 (Casselman et al., 2006) and pufferfish (Takifugu niphobles) (Gallego et al., 2013b). Sperm with higher percentage motility (Gallego et al., 2013b; Moccia and Munkittrick,

506 1987) and spermatozoa with higher mean swimming speeds had lower spz $\mathrm{egg}^{-1} \mathrm{ratios}$ to fertilise a high percentage of eggs (Casselman et al., 2006; Gallego et al., 2013b). In the 508 present study, sperm percentage motility was related positively with spz $\mathrm{egg}^{-1}$ ratio $\left(\mathrm{R}^{2}=\right.$ $0.83, \mathrm{P}=0.021)$. Senegalese sole sperm has variable and generally poor quality with low 510 percentage motility (González-López et al., 2020). In the present study as in other studies (Ramos-Júdez et al., 2019), the effect that percentage motility has on the spz egg ${ }^{-1}$ ratio

512 was removed by examining the relationship between the number of motile sperm and eggs fertilised. Many studies simply express total number of sperm (including immotile

514 sperm) in the spz $\operatorname{egg}^{-1}$ ratio, however, this is inaccurate and should be stated with the percentage motility of the sperm used. Although the practice of using total spz is accepted 516 in the literature it should only be applied to species that have little variation in motility and preferably high levels (close to $100 \%$ ) of motility amongst individuals.

518 In the present study, the quality of eggs did not appear to be related to the $\mathrm{spz} \mathrm{egg}^{-1} \mathrm{ratio}$ However, the low variation in egg quality $(82.6 \pm 9.2 \%)$ and $n(n=5)$ may have reduced 520 the possibility to determine a relationship. Previous studies are contradictory indicating that eggs with higher quality required more (Ramos-Júdez et al., 2019) and less

522 (Bombardelli et al., 2013) spz than low quality eggs. It would appear probable that both the quality and the characteristics of the unfertilised egg are implicated in the fertilisation 524 success. Good quality eggs would have more eggs to be fertilised and low quality eggs would have an environment with more space to encounter viable eggs amongst the

526 inviable eggs. In addition, fish eggs of some species have been shown to have no mechanisms to attract spz whilst other species eggs have chemical and physical properties 528 that guide the spz to the micropyle (Yanagimachi et al., 2017). The ability to attract spz to the eggs would in theory reduce the spz egg ${ }^{-1}$ ratio. These observations would suggest 530 number of motile spz per viable egg should be used to ensure egg viability does not affect the $\mathrm{spz} \mathrm{egg}^{-1}$ ratio. However, further work is required to determine the effect of egg quality on the spz $\mathrm{egg}^{-1}$ ratio. 


\subsection{Why do Senegalese sole have a low spz $\mathrm{egg}^{-1}$ ratio?}

534 Senegalese sole spawn as a female and male pair with no involvement of other individuals (Carazo et al., 2016) and spawning pairs show a degree fidelity during and between

536 spawning seasons (Fatsini et al., 2020; Martín et al., 2014). Therefore, Senegalese sole fertilisation does not involve sperm competition as all the sperm originates from a single

538 male and does not compete with sperm from other males. In addition, the two sexes swim in synchrony with the genital pores held close together (Carazo et al., 2016). The male

540 urogenital duct is slightly raised and the female oviduct forms a kind of well when eggs are being stripped (personal observations), which together with the closeness of the fish

542 during gamete liberation (Carazo et al., 2016) suggest that the male and female place the spz next to the eggs in very close proximity. Other studies have demonstrated that these

544 behavioural and reproductive strategies are related to low spz $\mathrm{egg}^{-1}$ ratios or low sperm production. Reducing the space of the fertilisation environment has been shown to reduce

546 the spz egg ratios ${ }^{-1}$ required (Bombardelli et al., 2013). Different species have very varied strategies and behaviours that will alter the space of the fertilisation environment, which 548 can range from mass spawning in aggregations in open water (Domeier and Colin, 1997; Ibarra-Zatarain and Duncan, 2015) to spawning between two fish in an enclosed space or 550 in very close proximity (Carazo et al., 2016; Tatarenkov et al., 2006). The spawning behaviour and number of individuals involved will influence the degree of sperm

552 competition that gametes must negotiate to achieve fertilisation. Sperm competition has been shown to influence fertilisation success and the number of spz that a species 554 produces (Parker and Pizzari, 2010; Stockley et al., 1997). Monogamy, and the absence of sperm competition was demonstrated to reduce testes size across different taxa and

556 monogamous fish species defined as spawning in a pair had significantly smaller testes compared to polyandrous species (group spawning of males with a female) (Baker et al.,

558 2020). Therefore, as has been suggested for fresh water fish (Kholodnyy et al., 2020), reproductive strategies and behaviour appear to be linked to gamete requirements to

560 achieve high rates of fertilisation. Consequentially, the reproductive strategy and behaviour of Senegalese sole support the described low spz production (García-López et

562 al., 2005; González-López et al., 2020) as well as the low spz egg ${ }^{-1}$ ratio for fertilisation (present study). It can be hypothesised that $\mathrm{spz} \mathrm{egg}^{-1}$ ratio is related to reproductive

564 strategies and sperm production, however, more work is required across a wide range of species to determine the existence of a relationship.

\section{$566 \quad 4.6$ Conclusion}

In conclusion, Senegalese sole require a low spz $\mathrm{egg}^{-1}$ ratio to achieve high percentages

568 of fertilisation both on an experimental scale and in proof-of-concept large-scale in vitro fertilisations. The low spz $\mathrm{egg}^{-1}$ ratio required to fertilise all viable eggs was consistent 570 with the reproductive behaviour and strategies of the species. The protocol $(200 \mu \mathrm{L}$ of sperm per $100 \mathrm{~mL}$ of eggs) described in the present study will enable the Senegalese sole aquaculture industry to operate sustainably and establish breeding programs. 
574

576

578

580

582

584

586

588

590

592

\section{References}

594

596

598

600

602

604

606

608

610

\section{Acknowledgements}

The authors would like to thank Josep Lluis Celades and the IRTA staff for technical assistance. Special thanks are also given for the participation and great enthusiasm to complete work to a high standard shown by Mario Villalta Vega and Alex Rullo Reverté, two work experience students from the IES Alfacs Escola d'Aqüicultura (http://aquicultura.insalfacs.cat/). This study has been supported with funding from the Spanish National Institute for Agronomic Research (Instituto Nacional de Investigación y Tecnología Agraria y Alimentación - INIA)-European Fund for Economic and Regional Development (FEDER) (RTA2014-0048) coordinated by Neil Duncan. The study was also supported and driven by discussions in the project 038433 _REARLING, funded by Portugal and the European Union through FEDER/ERDF, NORTE 2020, in the framework of Portugal 2020, coordinated by Isidro Blanquet (Sea8 Group, Povoa de Varzim, Portugal) and in collaboration with Joan Cerdá (IRTA) and Ignacio Giménez, (Rara Avis Biotec S.L., Valencia, Spain). In particular special thanks are given to Ignacio Giménez who refused an authorship after selflessly giving his advice to help improve sperm collection and storage. Participation by Wendy González-López was funded by a $\mathrm{PhD}$ grant from the National Board of Science and Technology (CONACYT, Mexico) and Sandra Ramos-Júdez by a PhD grant from AGAUR (Government of Catalonia) cofinanced by the European Social Fund.

Agulleiro, M.J., Anguis, V., Cañavate, J.P., Martínez-Rodríguez, G., Mylonas, C.C., Cerdà, J., 2006. Induction of spawning of captive-reared Senegal sole (Solea senegalensis) using different administration methods for gonadotropin-releasing hormone agonist. Aquaculture 257, 511-524. https://doi.org/10.1016/j.aquaculture.2006.02.001

Anguis, V., Cañavate, J.P., 2005. Spawning of captive Senegal sole (Solea senegalensis) under a naturally fluctuating temperature regime. Aquaculture 243, 133-145. https://doi.org/10.1016/j.aquaculture.2004.09.026

APROMAR, 2019. La acuicultura en España 2019, Asociación Empresarial de Acuicultura de España (APROMAR). APROMAR. http://www.apromar.es/ content/informes-anuales Accessed 17/08/2020

Babiak, I., Ottesen, O., Rudolfsen, G., Johnsen, S., 2006. Chilled storage of semen from Atlantic halibut, Hippoglossus hippoglossus L. Theriogenology 66, 2025-2035. https://doi.org/10.1016/j.theriogenology.2006.06.003

Baker, J., Humphries, S., Ferguson-Gow, H., Meade, A., Venditti, C., 2020. Rapid decreases in relative testes mass among monogamous birds but not in other vertebrates. Ecol. Lett. 23, 283-292. https://doi.org/10.1111/ele.13431

Beirão, J., Boulais, M., Gallego, V., O’Brien, J.K., Peixoto, S., Robeck, T.R., Cabrita, E., 2019. Sperm handling in aquatic animals for artificial reproduction. Theriogenology 133, 161-178. https://doi.org/10.1016/j.theriogenology.2019.05.004

Beirão, J., Soares, F., Herráez, M.P., Dinis, M.T., Cabrita, E., 2011. Changes in Solea senegalensis sperm quality throughout the year. Anim. Reprod. Sci. 126, 122-129. https://doi.org/10.1016/j.anireprosci.2011.04.009

Beirão, J., Soares, F., Herráez, M.P., Dinis, M.T., Cabrita, E., 2009. Sperm quality evaluation in Solea senegalensis during the reproductive season at cellular level. Theriogenology 72 , 1251-1261. https://doi.org/10.1016/j.theriogenology.2009.07.021

Bombardelli, R.A., Sanches, E.A., Baggio, D.M., Sykora, R.M., Souza, B.E. de, Tessaro, L., Piana, P.A., 2013. Effects of the spermatozoa: oocyte ratio, water volume and water 
temperature on artificial fertilization and sperm activation of cascudo-preto. Rev. Bras. Zootec. 42, 1-6. https://doi.org/10.1590/S1516-35982013000100001

Bromage, N., 1992. Propagation and stock improvement, in: Bromage, N., Shepherd, J. (Eds.), Intensive Fish Farming. Blackwell Science, Oxford, UK, pp. 103-153.

Brown, N., 2010. Halibut aquaculture in North America, in: Daniels, H., Watanabe, W. (Eds.), Practical FLatfish Culture and Stock Enhancement. Blackwell Publishing, Ames, lowa, USA.

Butts, I., Roustaian, P., Litvak, M., 2012. Fertilization strategies for winter flounder: effects of spermatozoa density and the duration of gamete receptivity. Aquat. Biol. 16, 115-124. https://doi.org/10.3354/ab00439

Butts, I.A.E., Trippel, E.A., Litvak, M.K., 2009. The effect of sperm to egg ratio and gamete contact time on fertilization success in Atlantic cod Gadus morhua L. Aquaculture 286, 89-94. https://doi.org/10.1016/j.aquaculture.2008.09.005

Cabrita, E., Soares, F., Beirão, J., García-López, A., Martínez-Rodríguez, G., Dinis, M.T., 2011. Endocrine and milt response of Senegalese sole, Solea senegalensis, males maintained in captivity. Theriogenology https://doi.org/10.1016/j.theriogenology.2010.07.003

Cabrita, E., Soares, F., Dinis, M.T., 2006. Characterization of Senegalese sole, Solea senegalensis, male broodstock in terms of sperm production and quality. Aquaculture 261, 967-975. https://doi.org/10.1016/j.aquaculture.2006.08.020

Carazo, I., Chereguini, O., Martín, I., Huntingford, F., Duncan, N., 2016. Reproductive ethogram and mate selection in captive wild Senegalese sole (Solea senegalensis). Span. J. Agric. Res. 14, e0401. https://doi.org/10.5424/sjar/2016144-9108

Casselman, S.J., Schulte-Hostedde, A.I., Montgomerie, R., 2006. Sperm quality influences male fertilization success in walleye ( Sander vitreus ). Can. J. Fish. Aquat. Sci. 63, 2119-2125. https://doi.org/10.1139/f06-108

Cejko, B.I., Żarski, D., Targońska, K., Krejszeff, S., Kucharczyk, D., Glogowski, J., 2010. Osmolality of Seminal Plasma as an Indicator of Milt Contamination with Urine Based on the Example of the Tench Tinca tinca (L.). Pol. J. Nat. Sci. 25, 287-298. https://doi.org/10.2478/v10020-010-0026-6

Chauvigné, F., González, W., Ramos, S., Ducat, C., Duncan, N., Giménez, I., Cerdà, J., 2018. Seasonal-and dose-dependent effects of recombinant gonadotropins on sperm production and quality in the flatfish Solea senegalensis. Comp. Biochem. Physiol. A. Mol. Integr. Physiol. 225, 59-64. https://doi.org/10.1016/j.cbpa.2018.06.022

Chauvigné, F., Ollé, J., González, W., Duncan, N., Giménez, I., Cerdà, J., 2017. Toward developing recombinant gonadotropin-based hormone therapies for increasing fertility in the flatfish Senegalese sole. PLOS ONE 12, e0174387. https://doi.org/10.1371/journal.pone.0174387

Chereguini, O., de la Banda, I.G., Rasines, I., Fernandez, A., 1999. Artificial fertilization in turbot, Scophthalmus maximus (L.): different methods and determination of the optimal spermegg ratio. Aquac. Res. 30, 319-324. https://doi.org/10.1046/j.1365-2109.1999.00326.x

Domeier, M.L., Colin, P.L., 1997. Tropical reef fish spawning aggregations: defined and reviewed. Bull. Mar. Sci. 60, 698-726.

Duncan, N., Carazo, I., Chereguini, O., Mañanós, E., 2019. Mating Behaviour, in: Munoz-Cueto, J., Mañanós-Sánchez, E., Sánchez-Vázquez, J. (Eds.), Biology of Sole. CRC Press, Boca Raton.

Fatsini, E., Carazo, I., Chauvigné, F., Manchado, M., Cerdà, J., Hubbard, P.C., Duncan, N.J., 2017. Olfactory sensitivity of the marine flatfish Solea senegalensis to conspecific body fluids. J. Exp. Biol. 220, 2057-2065. https://doi.org/10.1242/jeb.150318

670 Fatsini, E., González, W., Ibarra-Zatarain, Z., Napuchi, J., Duncan, N.J., 2020. The presence of wild Senegalese sole breeders improves courtship and reproductive success in cultured 
Gallego, V., Carneiro, P.C.F., Mazzeo, I., Vílchez, M.C., Peñaranda, D.S., Soler, C., Pérez, L., Asturiano, J.F., 2013a. Standardization of European eel (Anguilla anguilla) sperm motility evaluation by CASA software. Theriogenology 79, 1034-1040. https://doi.org/10.1016/j.theriogenology.2013.01.019

Gallego, V., Pérez, L., Asturiano, J.F., Yoshida, M., 2013b. Relationship between spermatozoa motility parameters, sperm/egg ratio, and fertilization and hatching rates in pufferfish $\begin{array}{lll}\text { (Takifugu niphobles). Aquaculture } & \\ \text { https://doi.org/10.1016/j.aquaculture.2013.08.035 }\end{array}$

416-417,

238-243.

García-López, Á., Martínez-Rodríguez, G., Sarasquete, C., 2005. Male reproductive system in Senegalese sole Solea senegalensis (Kaup): Anatomy, histology and histochemistry. Histol. Histopathol. 20, 1179-1189. https://doi.org/10.14670/HH-20.1179

Gibson, R.N., Stoner, A.W., Ryer, C.H., 2014. The behaviour of flatfishes, in: Gibson, R.N., Nash, R.D.M., Geffen, A.J., van der Veer, H.W. (Eds.), Flatfishes: Biology and Exploitation.

González-López, W.Á., Ramos-Júdez, S., Giménez, I., Duncan, N.J., 2020. Sperm contamination by urine in Senegalese sole (Solea senegalensis) and the use of extender solutions for short-term chilled storage. Aquaculture 516, 734649. https://doi.org/10.1016/j.aquaculture.2019.734649

Guzmán, J.M., Cal, R., García-López, Á., Chereguini, O., Kight, K., Olmedo, M., Sarasquete, C., Mylonas, C.C., Peleteiro, J.B., Zohar, Y., Mañanós, E.L., 2011. Effects of in vivo treatment with the dopamine antagonist pimozide and gonadotropin-releasing hormone agonist ( $\mathrm{GnRHa}$ ) on the reproductive axis of Senegalese sole (Solea senegalensis). Comp. Biochem. Physiol. A. Mol. Integr. Physiol. 158, 235-245. https://doi.org/10.1016/j.cbpa.2010.11.016

Guzmán, J.M., Norberg, B., Ramos, J., Mylonas, C.C., Mañanós, E.L., 2008. Vitellogenin, steroid plasma levels and spawning performance of cultured female Senegalese sole (Solea senegalensis). Gen. Comp. Endocrinol. 156, 285-297. https://doi.org/10.1016/j.ygcen.2008.02.002

Guzmán, J.M., Ramos, J., Mylonas, C.C., Mañanós, E.L., 2009. Spawning performance and plasma levels of $\mathrm{GnRHa}$ and sex steroids in cultured female Senegalese sole (Solea senegalensis) treated with different GnRHa-delivery systems. Aquaculture 291, 200-209. https://doi.org/10.1016/j.aquaculture.2009.03.024

Ibarra-Zatarain, Z., Duncan, N., 2015. Mating behaviour and gamete release in gilthead seabream (Sparus aurata, Linnaeus 1758) held in captivity. Span. J. Agric. Res. 13, e0401. https://doi.org/10.5424/sjar/2015131-6750

Kholodnyy, V., Gadêlha, H., Cosson, J., Boryshpolets, S., 2020. How do freshwater fish sperm find the egg? The physicochemical factors guiding the gamete encounters of externally fertilizing freshwater fish. Rev. Aquac. 12, 1165-1192. https://doi.org/10.1111/raq.12378

Linhart, O., Rodina, M., Bastl, J., Cosson, J., 2003. Urinary bladder, ionic composition of seminal fluid and urine with characterization of sperm motility in tench (Tinca tinca L.). J. Appl. Ichthyol. 19, 177-181. https://doi.org/10.1046/j.1439-0426.2003.00470.x

Liu, Xin-fu, Liu, Xue-zhou, Lian, J., Wang, Y., Zhang, F., Yu, H., Ma, A., Liu, S., Zhai, J., 2008. Large scale artificial reproduction and rearing of Senegal sole, Solea senegalensis Kaup. Mar. Fish. Res. 29, 10-16.

Mañanós, E., Duncan, N., Mylonas, C., 2008. Reproduction and Control of Ovulation, Spermiation and Spawning in Cultured Fish, in: Cabrita, E., Robles, V., Herráez, P. (Eds.), Methods in Reproductive Aquaculture, Marine Biology. CRC Press, pp. 3-80. https://doi.org/10.1201/9780849380549.sec1

Marrero-Alemán, C., González-López, W., Ramos-Júdez, S., Navarro, I., Duncan, N., 2019. Artificial fertilisation in Senegalese sole (Solea senegalensis): induction with GnRHa and 

Aquaculture Europe 19, European Aquaculture Society, Berlin, Germany.

Martín, I., Carazo, I., Rasines, I., Rodríguez, C., Fernández, R., Martínez, P., Norambuena, F., Chereguini, O., Duncan, N., 2020. Reproductive performance of captive Senegalese sole, Solea senegalensis, according to the origin (wild or cultured) and gender. Span. J. Agric. Res. 17, e0608. https://doi.org/10.5424/sjar/2019174-14953

Martín, I., Rasines, I., Gómez, M., Rodríguez, C., Martínez, P., Chereguini, O., 2014. Evolution of egg production and parental contribution in Senegalese sole, Solea senegalensis, during four consecutive spawning seasons. Aquaculture 424-425, 45-52. https://doi.org/10.1016/j.aquaculture.2013.12.042

Moccia, R.D., Munkittrick, K.R., 1987. Relationship between the fertilization of rainbow trout (Salmo gairdneri) eggs and the motility of spermatozoa. Theriogenology 27, 679-688. https://doi.org/10.1016/0093-691X(87)90061-6

Morais, S., Aragão, C., Cabrita, E., Conceição, L.E.C., Constenla, M., Costas, B., Dias, J., Duncan, N., Engrola, S., Estevez, A., Gisbert, E., Mañanós, E., Valente, L.M.P., Yúfera, M., Dinis, M.T., 2016. New developments and biological insights into the farming of Solea senegalensis reinforcing its aquaculture potential. Rev. Aquac. 8, 227-263. https://doi.org/10.1111/raq.12091

Mylonas, C.C., Duncan, N.J., Asturiano, J.F., 2017. Hormonal manipulations for the enhancement of sperm production in cultured fish and evaluation of sperm quality. Aquaculture 472, 21-44. https://doi.org/10.1016/j.aquaculture.2016.04.021

Norambuena, F., Estevez, A., Bell, G., Carazo, I., Duncan, N., 2012a. Proximate and fatty acid compositions in muscle, liver and gonads of wild versus cultured broodstock of Senegalese sole (Solea senegalensis). Aquaculture 356-357, 176-185. https://doi.org/10.1016/j.aquaculture.2012.05.018

Norambuena, F., Estévez, A., Mañanós, E., Bell, J.G., Carazo, I., Duncan, N., 2013a. Effects of graded levels of arachidonic acid on the reproductive physiology of Senegalese sole (Solea senegalensis): Fatty acid composition, prostaglandins and steroid levels in the blood of broodstock bred in captivity. Gen. Comp. Endocrinol. 191, 92-101. https://doi.org/10.1016/j.ygcen.2013.06.006

Norambuena, F., Estévez, A., Sánchez-Vázquez, F.J., Carazo, I., Duncan, N., 2012b. Self-selection of diets with different contents of arachidonic acid by Senegalese sole (Solea senegalensis) broodstock. Aquaculture 364-365, 198-205. https://doi.org/10.1016/j.aquaculture.2012.08.016

Norambuena, F., Mackenzie, S., Bell, J.G., Callol, A., Estévez, A., Duncan, N., 2012c. Prostaglandin ( $F$ and $E, 2$ - and 3-series) production and cyclooxygenase (COX-2) gene expression of wild and cultured broodstock of senegalese sole (Solea senegalensis). Gen. Comp. Endocrinol. 177, 256-262. https://doi.org/10.1016/j.ygcen.2012.04.009

Norambuena, F., Morais, S., Estévez, A., Bell, J.G., Tocher, D.R., Navarro, J.C., Cerdà, J., Duncan, N., 2013b. Dietary modulation of arachidonic acid metabolism in senegalese sole (Solea Senegalensis) broodstock reared in captivity. Aquaculture 372-375, 80-88. https://doi.org/10.1016/j.aquaculture.2012.10.035

Parker, G.A., Pizzari, T., 2010. Sperm competition and ejaculate economics. Biol. Rev. 85, 897934. https://doi.org/10.1111/j.1469-185X.2010.00140.x

Perchec Poupard, G., Paxion, C., Cosson, J., Jeulin, C., Fierville, F., Billard, R., 1998. Initiation of carp spermatozoa motility and early ATP reduction after milt contamination by urine. Aquaculture 160, 317-328. https://doi.org/10.1016/S0044-8486(97)00301-3

Prins, J., 2012. Product and Process Comparions, in: Croarkin, C., Tobias, P. (Eds.), NIST/SEMATECH e-Engineering Statistics Handbook. http://www.itl.nist.gov/div898/handbook/ https://doi.org/10.18434/M32189 
Ramos-Júdez, S., González, W., Dutto, G., Mylonas, C.C., Fauvel, C., Duncan, N., 2019. Gamete quality and management for in vitro fertilisation in meagre (Argyrosomus regius). Aquaculture 509, 227-235. https://doi.org/10.1016/j.aquaculture.2019.05.033

Rasines, I., Gómez, M., Martín, I., Rodríguez, C., Mañanós, E., Chereguini, O., 2013. Artificial fertilisation of cultured Senegalese sole (Solea senegalensis): Effects of the time of day of hormonal treatment on inducing ovulation. Aquaculture 392-395, 94-97. https://doi.org/10.1016/j.aquaculture.2013.02.011

Rasines, I., Gómez, M., Martín, I., Rodríguez, C., Mañanós, E., Chereguini, O., 2012. Artificial fertilization of Senegalese sole (Solea senegalensis): Hormone therapy administration methods, timing of ovulation and viability of eggs retained in the ovarian cavity. Aquaculture 326-329, 129-135. https://doi.org/10.1016/j.aquaculture.2011.11.021

Riesco, M.F., Valcarce, D.G., Martínez-Vázquez, J.M., Martín, I., Calderón-García, A.Á., GonzalezNunez, V., Robles, V., 2019. Male reproductive dysfunction in Solea senegalensis: new insights into an unsolved question. Reprod. Fertil. Dev. 31, 1104. https://doi.org/10.1071/RD18453

Rizzo, E., Godinho, H.P., Sato, Y., 2003. Short-term storage of oocytes from the neotropical teleost fish Prochilodus marggravii. Theriogenology 60, 1059-1070. https://doi.org/10.1016/S0093-691X(03)00108-0

Samarin, A.M., Amiri, B.M., Soltani, M., Mohammad, R., Kamali, A., Naghavi, M.R., 2011. Effects of storage duration and storage temperature on viability of stored ova of kutum (Rutilus frisii kutum) in ovarian fluid. Afr. J. Biotechnol. 10, 12309-12314. https://doi.org/10.5897/AJB11.919

Sanches, E.A., Caneppele, D., Okawara, R.Y., Damasceno, D.Z., Bombardelli, R.A., Romagosa, E., 2016. Inseminating dose and water volume applied to the artificial fertilization of Steindachneridion parahybae (Steindachner, 1877) (Siluriformes: Pimelodidae): Brazilian endangered fish. Neotropical Ichthyol. 14, e140158. https://doi.org/10.1590/1982-0224-20140158

Sarosiek, B., Dryl, K., Krejszeff, S., Żarski, D., 2016. Characterization of pikeperch ( Sander lucioperca ) milt collected with a syringe and a catheter. Aquaculture 450, 14-16. https://doi.org/10.1016/j.aquaculture.2015.06.040

Stockley, P., Gage, M.J.G., Parker, G.A., Møller, A.P., 1997. Sperm Competition in Fishes: The Evolution of Testis Size and Ejaculate Characteristics. Am. Nat. 149, 933-954. https://doi.org/10.1086/286031

Suquet, M., Billard, R., Cosson, J., Normant, Y., Fauvel, C., 1995. Artificial insemination in turbot (Scophthalmus maximus): determination of the optimal sperm to egg ratio and time of gamete contact. Aquaculture 133, 83-90. https://doi.org/10.1016/00448486(94)00395-5

Tatarenkov, A., Barreto, F., Winkelman, D.L., Avise, J.C., 2006. Genetic Monogamy in the Channel Catfish, Ictalurus Punctatus, a Species with Uniparental Nest Guarding. Copeia 2006, 735-741. https://doi.org/10.1643/0045-8511(2006)6[735:GMITCC]2.0.CO;2

Yanagimachi, R., Harumi, T., Matsubara, H., Yan, W., Yuan, S., Hirohashi, N., lida, T., Yamaha, E., Arai, K., Matsubara, T., Andoh, T., Vines, C., Cherr, G.N., 2017. Chemical and physical guidance of fish spermatozoa into the egg through the micropyle. Biol. Reprod. 96, 780799. https://doi.org/10.1093/biolre/iox015 